\title{
THEOBROMINE SODIUM SALICYLATE AS A VASODILATOR ${ }^{1}$
}

\author{
By TERESA McGOVERN, ELLEN McDEVITT, AND IRVING S. WRIGHT \\ (From the Vascular Clinic of the Department of Medicine of the New York Post-Graduate \\ Medical School and Hospital of Columbia University, New York)
}

(Received for publication August 15, 1935)

The object of our investigation was to corroborate, if possible, the claims made for theobromine and its salts as efficient vasodilators, suitable for use in the treatment of peripheral vascular disease.

The xanthine group has been investigated pharmacologically by many workers. Not all agree, however, on the coronary and circulatory effect. Sollman (1) states, “Its most important action is vasodilatation, by direct action on the vessels with moderate doses." Heathcote (2) finds that coronary flow is considerably increased in profused hearts, while Bock (3) states ". . . the action of caffeine is due to a depressant action on the vagus nerve endings." On the other hand, Smith and his co-workers (4) state that theobromine-sodio-salicylate in dilutions of $1: 25,000$ produced no change, or even decreased the coronary flow. It is not, therefore, surprising that the clinicians differ in the estimate as to the action of this group of drugs.

Theobromine has been in use for many years. Askanazy (5) forty years ago used it to relieve the pain of angina pectoris. Neuhof (6) twenty-two years ago used $40 \mathrm{cc}$. of a 5 per cent solution of theobromine-sodio-salicylate intravenously in cases of edema due to cardiorenal disease, and in some other types of renal disease, claiming favorable results. A careful study of this work, however, reveals that the results reported cannot be attributed to the drug alone, since Neuhof employed concomitantly therapeutic measures, any one of which might have accomplished the same results. Dock (7) in 1926 wrote, "In most cases of angina no relief was given, but in an important minority relief was immediate and complete. In one case of intermittent claudication due to arteriosclerosis complete and lasting results were noted." Scupham, in 1931 (8), reported favorably on the theobro-

\footnotetext{
${ }^{1}$ Aided by a grant from the Josiah Macy, Jr. Foundation.
}

mine, and again, in 1934 (9), he reported very encouraging results in thrombo-angiitis obliterans and arteriosclerosis with oral administration of the theobromine-sodio-acetate. Here, again, one is confused by the fact that other forms of therapy of known value were employed concomitantly.

Newell and Allen (10) also reported favorably on the vasodilating effect of theobromine when given orally and theobromine sodium salicylate, when given intravenously. They felt, however, that the clinical value of these drugs was open to question.

Since theobromine compounds had not been tried in our Clinic, it was decided to determine whether we could obtain sufficient evidence of their vasodilating action to warrant their use in our recommended list of therapeutic procedures of value in the treatment of peripheral vascular disease. We were interested primarily in the total increase in circulation to the extremities, rather than in determining whether such dilatation was caused by increased action of the collateral vessels or by decrease in the spasm of the major arteries.

In the usual treatment of peripheral vascular disease in our Clinic, all patients are given instructions in the hygiene of the extremities. During cold weather, they are advised to wear warm socks or stockings and properly fitted shoes. The hands are protected by warm gloves and, when possible, the female patients use muffs. Rye bread and tobacco (11) are forbidden. Following these basic instructions, the patient is given the single therapeutic agent selected, be it typhoid vaccine (11a) intravenously, one of the choline compounds $(12,12 \mathrm{a})$, tissue extract (13), passive vascular exercise (14), or whatever procedure which seems, in our experience, to afford the greatest hope of relief for the individual case. No other therapeutic agent is used in conjunction with the selected treatment. The criteria for improvement are: increased oscillometric readings, increased surface temperature 
readings, improved capillary activity (15), relief of pain of whatever type and healing of tissue.

In addition, where indicated, experimental studies such as described below are utilized to determine the effect of a given method.

\section{SELECTION OF PATIENTS}

Twenty patients suffering from one or more of the following diseases were used: Raynaud's disease, thrombo-angiitis obliterans, recurrent ulcerative phlebitis, varicose veins with ulcers, arthritis, frostbite of feet (uncomplicated), frostbite of feet with thrombosis of major arteries of both lower extremities up to and including the femorals, diabetes with early Dupuytren's contraction, diabetic neuritis and sclerosis of ulnar arteries, pituitary disease with paresthesia of fingers, atrophic ulcer at amputation site (due to accident twenty years ago). In no instance were the major vessels to the hands organically occluded.

\section{PROCEDURE}

Only one patient was studied at a time. In each case, a purine free diet was given for twentyfour hours preceding the test. Breakfast at 7 a.m. consisted of fruit juice, cooked white cereal, with milk and sugar (except in diabetic patients), and milk to drink. No medication was used during the twenty-four hours preceding the test, except insulin for diabetic patients. All experiments were carried out in the same room. All patients were, therefore, studied under the same basic conditions, except that the temperature of the room was not identical for each case. The maximum variation in room temperature during an experiment was $1.3^{\circ} \mathrm{C}$. in one instance. All other experiments were performed with variations of from 0.1 to $0.9^{\circ} \mathrm{C}$. All drafts were excluded. The humidity was not controlled. The patient was seated in a comfortable armchair, with the lower extremities exposed to the knees, feet insulated from the cold floor, hands and arms resting at the level of the heart. The third finger of the right hand was attached to the thermocouple junction of an automatic, right-hand, potentiometer (Micromax, Leeds and Northrup). Other temperature readings, taken with the non-recording potentiometer, were room temperature, mouth, forehead, right and left cheek, first, third and fifth fingers of right and left hands, first, third and fifth toes of right and left feet (finger and toe readings taken half-way between the nailfold and the first joint). Pulse and respiratory rates were counted for a full minute, and blood pressure was recorded. Oscillometric reading was taken on the lower third of the left leg and capillary observations on fingers of the left hand.

Theobromine-sodio-salicylate (powdered), 2.6 grams (40 grains) in $180 \mathrm{cc}$. of water, was administered orally to ten of the twenty cases. This dosage was selected as the maximum which could be taken easily and without danger of gastrointestinal upset. The dose is larger than the average used in clinical medicine. Ten cases were given theobromine-sodio-salicylate by iontophoresis, starting with a 1.25 per cent solution of the drug in water. In certain of these patients, the percentage was increased in subsequent experiments to $2.5,5$ and 10 per cent. The 10 per cent solution was given from the negative pole, and, a week later, from the positive pole, to the same individuals.

Experiments were not begun until the patient was stabilized satisfactorily in regard to all factors studied. The duration of this control period varied greatly. One patient required fifty minutes, whereas another took three hours and fortyseven minutes; the average was two hours and seventeen minutes. Patients emptied the bladder before and after the control period. The urine was discarded, except in the cases where the drug was given by iontophoresis. The bladder was again emptied at the end of the experiment, and the urine measured and discarded, except in certain of the iontophoresis cases. The urine from two of the latter group in which a 10 per cent solution was used on the positive and negative poles was collected for the next sixteen hours and studied for the estimation of the theobromine content. This step was taken to make sure that a measurable amount of the drug had been absorbed.

No untoward symptoms were noted in any of the experiments. The patients were given a book, a magazine or newspaper to read or were engaged in light conversation to take their minds off the experiment. Following administration of the drug, readings were taken for four hours. 


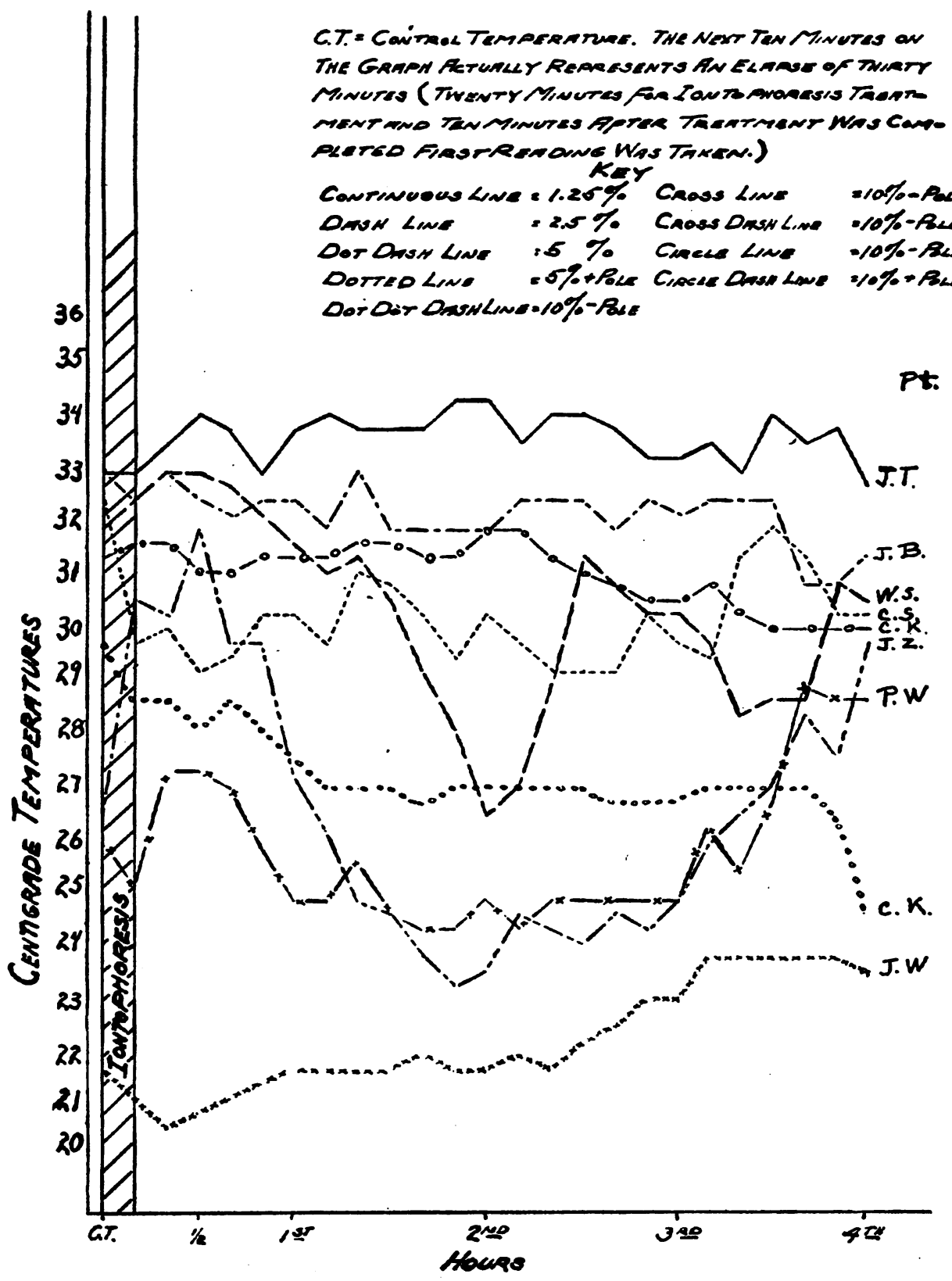

Fig. 1. Analyzing the curves of the iontophoresis experiments, the following facts are significant:

$J . W .13$ temperature readings above control temperature. 6 temperature readings same as control temperature. 5 temperature readings below control temperature. Ten of the thirteen increased readings occur in the last one and one-half hour of the experiment. Five below occur in the first hour.

$C$. $K$. All below control temperature.

$J$. $Z$. 10 temperature readings above control temperature. 1 temperature reading same as control temperature. 13 temperature readings below control temperature. Of the ten above the control temperature, six occur in the first hour and four in the last hour.

$P$. $W .7$ temperature readings are above control tem- perature. 2 temperature readings are same as control temperature. 15 temperature readings are below control temperature. Of seven above the control temperature, three occur in the first hour and four occur in the fourth hour.

$W . S$. Five above control temperature occur in the first hour. Nineteen are below control temperature.

$C$. $K$. 6 above control temperature. 6 same as control temperature. 12 below control temperature. Of the six above, two occur in first hour, two occur in second hour, and two occur in third hour.

$C$. $S$. All below control temperature.

$J$. B. All below control temperature.

J. T. All above control temperature. 


\section{RESULTS}

1. Temperature of the skin at the finger tips. The temperature of the finger tips attached to the automatic recording potentiometer, in two of the patients taking the drug orally, was recorded as above that of the control period $\left(3\right.$ and $1.2^{\circ} \mathrm{C}$. respectively). The remaining eight patients who received the drug by mouth showed a lowering in the surface temperature of from 0.6 to $7.8^{\circ} \mathrm{C}$., with an average drop of $2.8^{\circ} \mathrm{C}$. Of the cases given the drug by iontophoresis, in four an increase in the temperature readings were recorded,

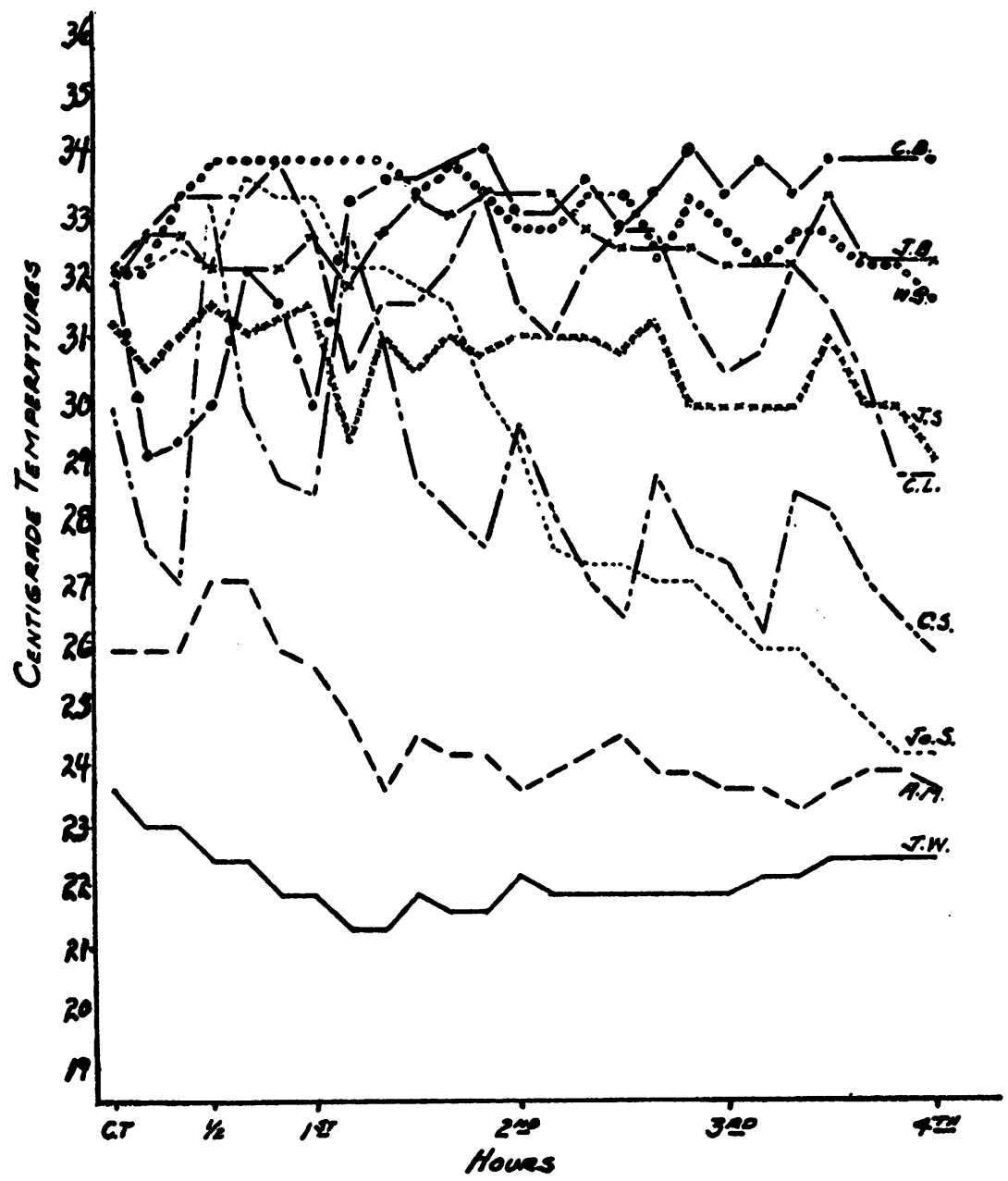

Fig. 2. Curves Represent the Temperature Reading Recorded by the Automatic Potentiometer. Drug Given Orally

Analyzing the curves of the oral administration of the drug, the following significant facts are observed:

$J$. $W$. All temperature readings are below the control temperature.

A. $M$. Two temperature readings recorded above the control temperature. Three readings are the same, and twenty are below the control reading.

$J$. S. Four temperature readings are above control temperature. Four are the same as control temperature, and seventeen are below the control temperature.

$C$. $S$. Three temperature readings are above, one the same, and twenty below the control temperature.
$C$. $L$. Nine temperature readings are above, three the same as, and thirteen below the control temperature.

$J$. $S$. Two above, two same and twenty are below the control temperature.

$W . S$. Seventeen are above, five the same as, and the last two are below the control temperature.

$J$. B. Twenty-four are above the control temperature.

$C$. $B$. Eighteen are above, one the same as, and five below the control temperature. These occur in the first hour after the drug is given. 
after the third hour, of $1.2,1.7,2.8$, and $3.6^{\circ} \mathrm{C}$. The remaining six patients showed lowered readings of $1.2,1.7,2.3,2.8$ and $5.6^{\circ} \mathrm{C}$., with an average drop of $3.1^{\circ} \mathrm{C}$. The following recordings were taken by the non-recording potentiometer.

2. Mouth temperature. In four cases, no variation was noted. Eight showed a rise above the control period of 0.2 to $1.3^{\circ} \mathrm{C}$., and eight a fall below the control period of 0.4 to $1.5^{\circ} \mathrm{C}$.

3. Forehead temperature. Two patients showed no variation. Ten showed a rise of 0.2 to $0.8^{\circ} \mathrm{C}$. above and eight a fall of 0.2 to $1.4^{\circ} \mathrm{C}$. below the control temperature.

4. Temperature of the cheeks. Eight patients showed a rise above the control period of from 0.2 to $1.2^{\circ} \mathrm{C}$., an average of $0.82^{\circ} \mathrm{C}$. Ten showed a fall of from 0.2 to $1.7^{\circ} \mathrm{C}$., with an average drop of $0.91^{\circ} \mathrm{C}$. In two patients, the femperature of one cheek was higher and the other lower than the control temperature.

5. Temperature at the tips of the fingers. Space will not permit the recording of all temperature readings of the five fingers. Suffice to say that four patients showed increased readings, and fourteen decreased readings.

6. Temperature at the tips of the toes, without exception, gave lower readings.

7. The pulse did not vary in two cases. In five cases, the variation above the control was 2 to 6 beats per minute with an average increase of 3.4. In thirteen cases, it decreased 2 to 13 beats per minute with an average drop of 4.6.

8. Respiratory rate, in a few instances, varied as much as 4 per minute. Other patients showed no greater variation than 1 or 2 .

9. Blood pressure showed no change in eleven cases, an increase above control readings in five, and a decrease in four.

10. Oscillometric readings were unchanged in four patients, slightly increased in eleven and dedecreased in four.

11. Capillary flow was slower in all cases.

12. There was no consistent diuresis.

13. Table I shows the results of the studies of the theobromine excreted as such in the urine following the use of iontophoresis of a 10 per cent solution of theobromine sodium salicylate. (Determination by the method of Günzberg (16).) The minute amount measurable is in part ex- plained by the fact that only 32 per cent of the theobromine is excreted in the urine as such, whereas the great part leaves the body as heteroxanthines (1). In the two experiments in our. series, an increase was noted, indicating that theobromine was absorbed through the skin by the method of iontophoresis.

TABLE I

Effect of iontophoresis of 10 per cent solution of theobromine sodium salicylate on the excretion of theobromine in the urine

\begin{tabular}{llc} 
Case & \multicolumn{1}{c}{ Time } & $\begin{array}{c}\text { Theobromine } \\
\text { grams per } 100 \text { cc. } \text { urine }\end{array}$ \\
I & Immediately after & 0.003 \\
& 4 hours later & 0.0045 \\
II & 16 hours later & 0.014 \\
& Before & 0.006 \\
& 4 hours later & 0.018 \\
& 16 hours later & 0.025
\end{tabular}

The object of vasodilatation in the treatment of peripheral vascular disease is to make available to the local tissues an increased blood supply. When this is accomplished, the results are decreased pain and the healing of the tissue. There are numerous methods and drugs by the use of which these results may be obtained. It is doubtful whether a so-called "vasodilating" drug which does not produce a measurable increase in surface temperature in the majority of patients in such experiments as those above described is of sufficient value to be of use in the treatment of this group of diseases.

\section{CONCLUSION}

We conclude that theobromine sodium salicylate, in the dosage and by the methods of administration used, is too unreliable and feeble a vasodilator to be of value in the treatment of peripheral vascular disease.

\section{BIBLIOGRAPHY}

1. Sollman, T., Manual of Pharmacology. W. B. Saunders Co., Philadelphia, 1932, 4th ed., p. 277.

2. Heathcote, R. St. A., The action of caffeine, theobromine, and theophylline on the mammalian and batrachian heart. J. Pharmacol. and Exper. Therap., 1920, 16, 327.

3. Bock, J. (Quoted from Heathcote (2)). Ueber die Wirkung des Coffeins und des Theobromins auf das Herz. Arch. f. exper. Path. u. Pharmakol., $1900,43,367$.

4. Smith, F. M., Miller, G. H., and Graber, V. C., The effect of caffein sodio-benzoate, theobromin sodiosalicylate, theophyllin and euphyllin on coronary 
flow and cardiac action of the rabbit. J. Clin. Invest., 1925, 2, 157.

5. Askanazy, S. (Quoted from Dock (7)). Klinisches über Diuretin. Deutsches Arch. f. klin. Med., 1895, 56, 209.

Ioddiuretal gegen stenokardische und asthmatische Zustande. Munchen. med. Wchnschr., 1922, 69, 967.

6. Neuhof, S., Intravenous injections of theobrominesodium-salicylate. New York State J. Med., 1913, 98, 814.

7. Dock, W., The use of theobromine for pain of arteriosclerotic origin. California and West. Med., 1926, 25, 636.

8. Scupham, G. W., Some clinical observations on the use of theobromine in peripheral vascular disease. J. Clin. Invest. (Abstract), 1931, 10, 165.

9. Scupham, G. W., Effect of theobromine on peripheral vascular disease. Clinical observations. Arch. Int. Med., 1934, 54, 685.

10. Newell, Cecil E., and Allen, Edgar V., The peripheral vasodilating effect of theobromine given orally and intravenously. J. Tennessee M. A., 1934, 27, 291.

11. Wright, Irving S., and Moffat, Dean, The effects of tobacco on the peripheral vascular system. J. A. M. A., 1934, 103, 318.

11a. Wright, Irving S., The modern medical treatment of disease of the peripheral vascular system. M. Clin. North America, 1934, 17, 1429.

12. Kovacs, Joseph, Iontophoresis of acetyl-beta-methylcholin chlorid in the treatment of chronic arthritis and peripheral vascular disease. Am. J. M. Sc., 1934, 188, 32.

12a. Kovacs, J., Saylor, L., and Wright, I. S., The pharmacological and therapeutic effects of certain choline compounds. Am. Heart J. (In press).

13. Duryee, A. W., Tissue extract in the treatment of peripheral vascular disease. Tr. Am. Therap. Soc., 1935, 35.

14. Short, J. J., A simplified apparatus for the application of suction and pressure to the lower extremities in peripheral vascular disease. J. A. M. A., 1935, 104, 1814.

15. Wright, I. S., The clinical value of human capillary studies. J. A. M. A., 1933, 101, 439.

16. Günzburg, L., Uber Theobrominausscheidung und Theobromindiurese. Biochem. Ztschr., 1922, 129, 549. 